\title{
The Institute of Coding: A University-Industry Collaboration to Address the UK's Digital Skills Crisis
}

\author{
James H. Davenport*, Tom Crick ${ }^{\dagger}$, Rachid Hourizi* \\ ${ }^{*}$ Department of Computer Science, University of Bath, Bath, UK \\ Email: \{j.h.davenport,r.hourizi\}@bath.ac.uk \\ ${ }^{\dagger}$ School of Education, Swansea University, Swansea, UK \\ Email: thomas.crick@swansea.ac.uk
}

\begin{abstract}
The Institute of Coding (IoC) is a new $£ 40 \mathrm{~m}+$ initiative by the UK Government to "transform the digital skills profile of the country". In the context of widespread national and international educational and economic policy interventions, it responds to the apparently contradictory data that the United Kingdom (UK) has a digital skills shortage across a variety of sectors, yet its higher education system produces computing graduates every year who end up unemployed, or underemployed.

The Institute is a large-scale national intervention to address some of the perceived issues with formal educational routes versus industry-focused skills and training, for example: technical skills versus "soft" or "work-ready" skills; industry-readiness versus "deep education"; inclusion and diversity of the current and future technical workforce; and managing expectations for the broad digital, data and computational skills demands of employers across a wide range of economic sectors. Alongside these activities at the higher education/industry interface, we have also seen substantial computer science curriculum reform across the four nations of the UK.

In this paper, we describe the background, evidence base and rationale for the IoC (especially within the complex UK policy context); its key themes, current activities and outputs; as well as anticipate its likely impact over the coming years. Furthermore, we reflect on the potential replicability of aspects of the Institute (and related initiatives in the UK) to other nations or regions with similar ambitions to address the "digital skills crisis".

Index Terms-Digital skills, Programming, Computer science education, Undergraduate education, Graduate education, Industry collaboration
\end{abstract}

\section{INTRODUCTION}

We are frequently being told that this is "the digital age", and that we "live in a knowledge economy"1, with "software eating the world" [2]; nevertheless, the impact of digital on all of our lives is clear. From entertainment and communication, via the power and reach of an oligopoly of social media platforms, with "algorithms" influencing what news we consume, or making decisions that affect us every day; to education, health and social care, through to innovation in public services [3]. We are also seeing the emergence of artificial intelligence and machine learning as general-purpose technologies that could transform whole industries and even re-invent the process of invention itself [4], [5]. What does

\footnotetext{
${ }^{1}$ Despite the debunking by Friesen [1].
}

this mean for education systems, national curricula and skills training - from compulsory, through to post-compulsory, into lifelong learning?

\section{A. Defining the "Digital Economy"}

Providing a comprehensive definition of the 'digital economy' is challenging; the Organisation for Economic Cooperation and Development's (OECD) 2002 definition of the Information and communication technology (ICT) sector does not provide much insight: "... a combination of manufacturing and services industries that capture, transmit and display data and information electronically" [6]. According to the current - but published in 2007! - UK Standard Industrial Classification of Economic Activities [7], the "Information and Communication" sector includes telecommunications, computer programming, information services, as well as a wide range of creative, publishing and broadcasting activities. Formal sector classifications aside, it is clear that while the UK has had a traditional vertical 'IT and Telecoms' sector, it also increasingly has a crucial enabling and facilitative horizontal digital sector. In essence: there is no such thing as the 'digital economy' - our economy is digital. While this situation is certainly not unique to the UK, it is perhaps exemplified by some of the grand challenges identified as part of the UK Industrial Strategy [8], published in 2017: from precision medicine, manufacturing and future materials, to creative industries clusters and next generation services, through to driverless cars and smart cities [9].

In 2018, the UK digital sector (as defined by OECD Standard Industry Classifications) comprised of 1.5 million jobs ( $4.5 \%$ of the total number of jobs in the UK), the highest number for the sector (and a 16.1\% increase) since 2011 [10]. $49.7 \%$ of these are in "Computer programming, consultancy and related activities": precisely the area to which the Institute of Coding is aimed. Its workers are more productive, on average, by $£ 10,000$ per worker and jobs requiring digital tech skills command higher salaries, at $£ 42,578$ compared to $£ 32,477$ for those that do not. Despite the stereotype that digital tech jobs are for "millennials", $72 \%$ of workers are aged over 35; however, only $19 \%$ of the UK digital tech workforce 
is female [11]. Indeed, the Institute of Coding announcement in 2018 quoted the even more pessimistic "In 2017, female programmers and software developers made up just 3.9 per cent of tech and telco professionals in the UK" [12].

\section{B. Education and Skills Policy}

Globally, there are a plethora of high-profile initiatives and interventions to address the wider societal challenge, and the corresponding skills shortages, of our digital world [13]. While there is a strong socio-economic focus, it should not just be about jobs: we want, and need, a digitally competent, capable and engaged citizenry. But this idealistic ambition provides significant challenges for long-term, coherent, sustainable policymaking and investment. More importantly, what do we mean by digital skills? In recent years, we have seen a multitude of policy reviews and reports from across government, academia, think tanks, learned societies and charities that have attempted to encapsulate some of the issues, as well as identifying potential solutions. At least three recent UK Parliamentary Select Committee inquiries [14]-[16] have, wholly or in part, focused on the 'digital skills crisis'. They have all made a number of specific recommendations, from curriculum and qualifications reform, ensuring young people are safe online, improving professional learning for practitioners, investment in infrastructure, developing effective pedagogies and the wider educational research base in the UK, through to terminology, fixing 'leaky pipelines' and changing the wider public perceptions of digital/technology disciplines.

Alongside substantial curriculum reform across the UK [17]-[19], including a new national curriculum in England [20] and emerging reform in Wales [21]-[23], we have also seen significant changes to the available qualifications, based on perceived rigour, content, distinctiveness and modes of assessment. The publication in 2017 by the Royal Society of a follow-up to their 2012 report [24] on computing education in the UK [25] framed some of these national challenges in the context of computing for all, calling for a coherent strategy so that all learners are equipped and empowered with the necessary skills to be effective in the digital world.

However, it is clear that from all of these various reviews, reports, activities, initiatives and interventions, there remains a lack of policy coherency and connectedness - more so when it cuts across ministerial portfolios, or requires multiyear coordinated support. In this paper we frame some of these strategic challenges - and opportunities - and introduce the Institute of Coding ( $\mathrm{IoC}$ ), a new $£ 40 \mathrm{~m}+$ initiative by the UK Government (but focused on England, with related activity in Wales) to transform the digital skills profile of the country [26].

The structure of the paper is as follows. In Section II we attempt to define the wider problem through the lens of graduate employment and earnings; this is followed in Section III by the UK higher education policy context and the skills mismatch respectively; in Section IV we present the Institute of Coding, its key themes, activities and outputs in Section V, finishing with future work and the potential replicability of aspects of the Institute in Section VI.

\section{A Note on Nomenclature}

While in many instances throughout this paper we will refer to the United Kingdom (UK) - consisting of the four nations of England, Scotland, Wales and Northern Ireland - many of the initiatives, approaches and funding models are specifically focused on England (or England and Wales), as a number of policy areas, including education and skills, are devolved to the respective national governments. We will attempt to be as clear as possible when referring to specific interventions across or between the four nations.

\section{So What's THE PROBLEM?}

Superficially, the employment outlook for computing graduates in the UK looks excellent. A 2015 report from the UK Commission for Employment and Skills [27, p. 74] states:

..."the digital sub-sector will need 518,000 workers for roles in the three highest skilled occupational groups. However, over the last ten years only 164,000 individuals graduated from a first degree in computer science."

This is beneficial to the individual: according to a 2011 UK Government report on economic returns from higher education qualifications [28, Figure 4], "mathematical and computer sciences" have the second highest earnings return of all subjects (overtaken only by "medicine and dentistry"). The country profits from this as well: per head, it is the fourth most beneficial subject to the UK [28, p. 16]. Nevertheless, despite the headline success in a variety of UK Government reports, the employment figures are not good, and the earnings data are patchy.

\section{A. Graduate Employment}

Further to the 2015 UK education and skills report [27], the following was highlighted in the 2016 UK Government review of computer sciences degree accreditation and graduate employability [29], led by Sir Nigel Shadbolt:

"In this context, apparently high rates of unemployment ${ }^{2}$ amongst graduates of Computer Sciences and other STEM ${ }^{3}$ courses demanded an explanation.

A significant explanation is "There are notable differences in the characteristics of Computer Sciences entrants compared to entrants in other STEM subjects" [29, \2.6]: fewer women, but:

$50 \%$ more mature students;

$16 \%$ more Black and Minority Ethnic (BME); and

${ }^{2} 11.7 \%$ six months after graduation (the then standard UK measure) at the time of [29], compared with a STEM average of $8.4 \%$. Note, however, that Computing is $20 \%$ of STEM [30, Table 1], so 'STEM-less-Computing' has a $7.6 \%$ unemployment rate.

${ }^{3}$ STEM is "Science, Technology, Engineering, Mathematics" for [29] and this paper. 
$40 \%$ more students from backgrounds where people have traditionally not participated in higher education (LPNs: low participation neighbourhoods).

UK Government data suggests that Mature, BME and LPN students all find getting jobs more difficult. However, for those students that do find jobs, the data are better, showing fewer students in "non-graduate jobs" or low-earning jobs than in STEM as a whole [29, Figure 6].

\section{B. Graduate Earnings}

If we look beyond purely getting jobs to the earnings ${ }^{4}$, the position (as described in official government figures [32], and analysed by the national media [33], which also allows the reader to break down the data by university and subject) is even less clear at a micro level, though at a macro level it supports the 2016 Shadbolt review findings [29].

At the macro level, we consider UK labour market returns [32, Table 5]. We focus on the 'Men' data as presented here, as there are (regrettably) many more than there are women in the cohorts, though the effects are similar. An "Ordinary Least Squares" (OLS) fit shows that a man reading Computing would earn $3.3 \%$ more than had he read a subject at random. If one corrects for prior attainment, this rises to $10.5 \%$, and $12.6 \%$ if other factors are taken into account. For reasons explained in the UK Government report [32, §4.2], the authors prefer "Inverse Probability Weighted Regression Adjustment" (IPRWA), and this moves the earning difference to $14.4 \%$. For men, the overall effect of these adjustments is to move Computing from being middle-of-the-pack [32, Figure 15] to fourth best [32, Figure 17], and for women it moves to seventh best [32, Figure 16]. Note that these are improvements on the average graduate earnings which are $£ 30,000$ /year for men and $£ 26,000 /$ year for women [32, p. 37]. Hence if a particular subject were sending students into a gender-neutral world, the women would be showing a $15 \%$ (£4,000/year) premium just to catch up with the men. It could be argued that maternity leave and other factors means that this is unrealistic, but the difference is due to much more than just that: [34, Figure 14] shows that for men the mean annual starting salary in Computing is $£ 25,500$, versus $£ 24,000$ for women.

\section{Per-University Earnings}

The $2018 \mathrm{BBC}$ article [33] allows us to break down the data underpinning the official government figures [32], resulting in challenging figures for Computing. Salary premiums, allowing for the factors described above, are reported separately for men and women, and only if there were at least 50 students of that gender in the five cohorts (graduation cohort 2007-8 to graduation cohort 2011-12) considered. This means that, of the 82 English universities reporting Computing, 80 report male data and 30 report female data -28 report both. Looking at

\footnotetext{
${ }^{4}$ Clearly not the only measure of job quality, or contribution to society, but at least it is measurable, and has been measured in the UK graduate longitudinal education outcomes (LEO) dataset [31], which tracks individuals through school, university and into the labour market, combining educational, tax and benefits data.
}

the 28 (see Figure 1), one's first impression is that the male and female data are uncorrelated: for example the two universities with male premiums just above $+£ 2500$ have female premiums of $+£ 9325$ and $-£ 5793$. There is in fact a definite $(p=0.0034)$ positive correlation, but a fairly weak one $\left(R^{2}=0.286\right)$. The best fit is $W=0.92672+0.53388 * M$. For the reasons explained at the end of the previous section, the ideal "genderneural" fit would be $W=4+M$. Both these lines are presented in Figure 1.

\section{Skills Mismatch}

There is a widespread and longstanding complaint in the UK that "students aren't industry-ready", or "there is a skills mismatch". Some of this is due to a misapprehension on the part of employers - and perhaps misunderstanding of the nature of education versus training (for example, exhibited by those outside the ICT industry itself, but seeking to hire people with "10 years experience of programming in Ruby"), but much of it is genuine. Previous work in this space has focused on the evidence base for how programming and software engineering is taught at degree level [35]-[37]. One of the key challenges for the university community is to better understand this complaint and how it can be address with closer industrial partnership and collaboration.

\section{UK Higher Education Policy Context}

After the UK Government's acceptance of a 2010 review into higher education funding and student finance [38], students in England pay probably the highest ${ }^{5}$ prices in the world for university (undergraduate) education: between $£ 6000$ and $£ 9000 /$ year for tuition alone. While this is normally covered by student loans repaid on an income-contingent basis, essentially through a $9 \%$ income tax premium, there is evidence that this contributes to lower rates of planned higher education participation by students from lower social class groups [40].

\section{A. Teaching Excellence Framework}

UK universities have been judged, very publicly, on their research for the last thirty years by a large-scale national Research Assessment Exercise (RAE), and its successor the Research Evaluation Framework (REF). This has led to many complaints, largely justified, that teaching, because it is not measured, is not taken as seriously as research, certainly in some of the leading research-intensive universities. Similar comments in the USA can be found in [41]. To counteract this, the Government introduced a "Teaching Excellence Framework" (TEF) ${ }^{6}$, with first grades published in June 2017. The ostensible aim of the TEF was to evaluate the quality of provision for each higher education provider within the UK. The initial version of the TEF produced a university-wide

\footnotetext{
${ }^{5}$ Or possibly second-highest after US students, but the US averages in [39, Table B5.1] conceal an enormous variation.

${ }^{6}$ Now renamed "Teaching Excellence and Student Outcomes Framework", which is somewhat more descriptive.
} 


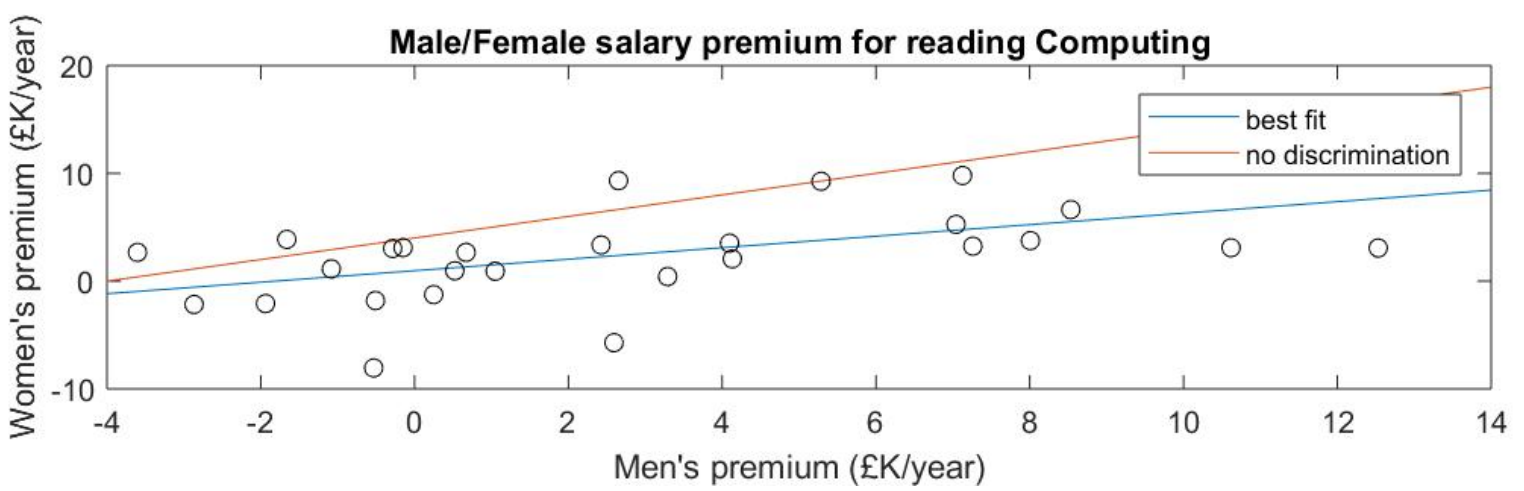

Figure 1.

assessment on a three-point (Gold-26\%/Silver-50\%/Bronze$24 \%$ ) scale ${ }^{7}$. It in fact used no direct assessment of teaching as such, primarily being based on historical statistical data, with some concerns raised on the robustness of the metrics and statistical analysis used to determine gradings [42].

In 2018, following an Institutional-level review undertaken in the previous year, the Office for Students (OfS) conducted a pilot of a national subject-based TEF. The objective was to provide sufficient data for prospective students to enable them to undertake an informed decision about their choice of University and subject of study. This was particularly pertinent to the UK context as the funding of higher education has shifted, following several policy changes [38], from students receiving means-tested Government grants to undertaking a loan to pay for their tuition.

The TEF's reliance on employment metrics pre-supposes a strong correlation between the quality of provision and the employment prospects/performance of the students. This can be challenging for some disciplines (e.g. income earning potential is not equally distributed across all subjects). The intention however is clear. In the context of students paying their own tuition fees, quality of provision is being linked to future employment prospects. This represents an opportunity for UK higher education computing provision. Those programmes, characteristic of most in computer science, that contain a placement/internship, are professionally-accredited and whose curriculum is informed by an employer-led advisory board are well-placed to do well in the TEF.

\section{B. Degree Apprenticeships}

The UK Government launched "Degree Apprenticeships" in 2015 [43], which were described by the then Prime Minister as "combining a full degree with the real practical skills gained in work and the financial security of a regular pay packet". The employer pays the tuition cost, but via a national Apprenticeship Levy [44], essentially a $0.5 \%$ payroll tax; large employers (total payroll over $£ 3 \mathrm{~m}$ ) will find there is no net cost, while smaller employers can claim $90 \%$ of the cost back from the government.

\footnotetext{
${ }^{7}$ For current scores, see: https://www.officeforstudents.org.uk/advice-andguidance/teaching/tef-outcomes/
}

Degree Apprenticeships can be either "Level 6" (undergraduate/BSc level) or "Level 7" (postgraduate/MSc level"). The Level 6 ones last three to five years, but typically four ${ }^{8}$. The details of Level 7 apprenticeships have only just been approved at the time of writing [45], so it is hard to determine how they will work in practice. However, the entire Degree Apprenticeship mechanism does seem to be geared more to large companies capable of supporting a bespoke programme, as for example is happening in Accountancy, where the "Big Four" firms are enthusiastically supporting such programmes". How well it can adjust to smaller high-technology companies has yet to be seen.

\section{Sandwich Years}

In the UK context, a university course that includes a period working in industry (which may also include government, charities, etc) is generally called a "sandwich" course, and in North America the term "co-op" is generally used. The most common model in Computing in England, where the vast majority of students study three-year Bachelor's degrees, is a year's placement in industry between the second and final years of study. This is remarkably successful in computing. The University of Bath has run such courses since its founding (1966), with about $80 \%$ of students opting to take the sandwich year. There is statistical evidence for its success wherever it is used in the $\mathrm{UK}^{10}$ :

"...those studying sandwich courses enjoy the lowest levels of unemployment (6\% sandwich vs $15 \%$ nonsandwich), the lowest levels of non-graduate level employment ( $6 \%$ sandwich vs $25 \%$ non-sandwich), and graduates from sandwich courses are twice as likely to be earning over $£ 20,000$ compared to those who did a standard degree." [29]

A simplistic remedy would be to require that all students study sandwich degrees, but this has numerous challenges:

\footnotetext{
${ }^{8}$ One such is detailed at http://www.aston.ac.uk/study/degreeapprenticeships/employers/degree-apprenticeship-programmes/digital-andtechnology-solutions-degree-apprenticeship/

${ }^{9}$ For example: https://www.pwc.co.uk/careers/school-jobs/jobs/flying-startdegrees.html

${ }^{10}$ And at least anecdotal evidence elsewhere: "the co-op system is a major reason for our [University of Waterloo] success" [46].
} 
1) Some students do not wish to, often for valid reasons;

2) The supply of employers willing to offer such placements is limited, and often they are only offered to a limited number of universities with whom the employer has built up relations, often going back decades;

3) The university needs to invest in the process: a successful sandwich year programme is not a matter of simply allowing students to intermit their studies.

Hence we should ask ourselves why such courses are so successful (if indeed they are: there is a possible confounding factor, in that, for those universities with scant support for the sandwich system, those students that do take a sandwich year will tend to be the more self-motivated ones, who would probably do well anyway). There appears to be two classes of reasons: those intrinsic to the sandwich process, and the skills the sandwich process confers. The first class is easy to understand: the employer can view the year as a year-long assessment phase before deciding whether to offer a permanent job. From the authors' institutional experience, about 2/3 of sandwich placements result in job offers to the student. However, it is the second class that we need to investigate in the hope that non-sandwich courses can learn from them.

\section{The Institute of Coding}

\section{A. Structure}

Formally announced in 2018 [12], but foreshadowed in 2015 [47], the Institute of Coding (IoC) ${ }^{11}$ is one of the UK Government's latest responses to the "digital skills challenge" [26]. The IoC brings together a consortium ${ }^{12}$ of research- and teaching-focused universities (primarily based in England due to the origin of the core funding, along with two Welsh institutions co-funded through a separate mechanism), large corporates, small- and medium-sized enterprises (SMEs), established industry groups, experts in the delivery of distance/non-traditional learning and professional bodies to develop and deliver innovative, industry-focused education across the UK. It is explicitly an industry-university collaboration, with the Government contributing at most $50 \%$ of the project funding.

It brings together for the first time traditional computer science departments and business schools, leaders in art and design, innovation in programme delivery, the industry backing of the UK's leading digital employers, and the leading professional bodies. The Institute's vision is that "every student leaves education with employment, and that employers and individuals across the UK have ready access to the skills they need to compete successfully in the global digital economy". It is structured around five priority themes:

\section{B. Theme 1: "University Learners"}

To increase the number of university learners and improve employability through innovative learning methods:

\footnotetext{
${ }^{11}$ https://instituteofcoding.org

${ }^{12}$ For full list of IoC partners, see: https://instituteofcoding.org/about/team/
}

This is aimed at understanding, and solving, the various "Skills Mismatch" problems to increase the number of university learners at Levels 6 and 7 (especially in key national priority areas such as data science and cybersecurity); as discussed previously, these problems can be quite subtle, and are not addressed by such broad requirements as [48, Requirement 2.3.1]. However, this theme aims to increase graduate employability via stronger employer links; hence the Institute is also looking at accreditation, with a view to producing more detailed records, essentially e-portfolios, of skills achieved, embedding innovative learning methods into material and delivery across institutions.

\section{Theme 2: "The Digital Workforce"}

To create learning that meets employer needs, enriches the student experience and provide in-work and flexible learning options that are viable at scale:

This theme aims to explore alternative delivery models, in an effort to identify and synthesis best practice - for both specialist and generalist provision, as well as educational training and professional development. There is a strong strand of lifelong learning: it aims to champion the role of the university as a teaching and learning partner/provider to equip learners for a career rather than specific jobs. In practice this is likely to be largely aimed at degree apprenticeships (see $\S$ III-B) in the short to medium term, to draw in more universities to provide Degree Apprenticeships and other related course models. These are still in their very early days in computing, and we hope that the Institute will enable best practice sharing from the beginning. In terms of content, as opposed to pedagogic practice, this theme is tightly linked with Theme 1 , notably in areas like cybersecurity, where there is a great shortage of non-proprietary teaching material.

\section{Theme 3: "Digitalising the Professions"}

To develop learning to address sector-specific digital skills needs, build an industrial strategy and deliver modular training:

This theme aims to develop a new industry-facing market of university-led, industry-valued provision in areas of strategic importance. The official description "to transform professions undergoing digital transformation" [12] is tautologous, but the consortium aims are to provide a flexible modular digital masters programme aimed at people in various professions where digital technologies are changing the job. Especially in sectors where serious upskilling in necessary (for example, across the creative economy, automotive, manufacturing, healthcare, the financial sector, etc), and also to provide various short taster courses in order to widen the reach of digital skills. As for Theme 2, this will be sharing content with Theme 1 .

\section{E. Theme 4: "Widening Participation"}

To develop a path from first contact to employment, removing barriers to entry and progress for poorly-served 
groups:

This is aimed at addressing the systemic issues with gender and diversity, as identified at the start of this paper: creating a pipeline, with tailored, inclusive curricula. Since the Institute bid was submitted and approved, salary data [32] (see Figure 1) has been released, which show the importance of a more nuanced study of the effect of gender in particular. The UK Government analysis [32] concentrated on gender, but we are hoping to do similar studies for computer science with regard to other protected characteristics such as ethnicity, to better understand and address the barriers, to share best practice across the sector.

Our current activity is a national survey to better understand the motivating factors for why different groups of people choose (or not) to train and work in digital. We are sampling three cohorts: working people, university learners and 15-18s. The focus is primarily on the gender difference, and different aspects within the female cohort.

\section{F. Theme 5: "Knowledge Sharing and Sustainability"}

To horizon scan for future digital skills need, disseminate and share best practice of the project, look at long-term sustainability and the management of the programme:

This theme is an underpinning theme for the others, providing longer-term horizon scanning, as well as supporting the evidence base, policymaking and sustainability through a "Digital Skills Observatory". The Observatory will work with employers and other stakeholders to identify and anticipate skills gaps through mapping current needs, to build up an evidence base of research, analysis and intelligence. A perverse, but totally natural, consequence of the REF has been the marginalisation of pedagogy research in the UK [49]. This is particularly acute in Computing, and can be quantified by noting that Australia, with less than $40 \%$ of the population of the UK and being over eight times further away, sends practically the same number of papers to the Koli Calling conference in Finland as the UK does [50]. Dissemination of good practice is also low: a 2016 national survey [36] was the first of its kind in the UK, despite the fact that they had been running for many years elsewhere [37]. This has also prompted a renewed look at how professional body accreditation can help foster and disseminate good practice [51].

\section{G. Key Challenges}

Delivering as much education as the Institute proposes presumes a supply of educators; this is a major challenge at all levels for computing in the UK [19], as it is in many countries. We have seen a number of challenges in the recruitment and retention of pre-university teachers (especially in England [52]), as well as issues with effectively scaling professional development opportunities at the national level [53] (for example, subject knowledge enhancement, pedagogic knowledge, as well and funding to access courses and higher degree programmes [23], [54]); hence all workpackages have aspects devoted to "educating the educators".

A further challenge is sustainability. The UK Government funding (for England) for the Institute is relatively short-term given the systemic challenges, and indeed will lapse before anyone graduates from a Level 6 (undergraduate/BSc) course or degree apprenticeship. Hence the Institute needs to build an ecosystem with its academic and industrial partners to become self-supporting in a very short timeframe. Furthermore, there are significant challenges to timing and coordinating devolved funding initiatives across the four nations of the UK for these types of interventions, especially with potentially diverging approaches to education and skills policy, including qualifications.

\section{IMPACT TO DATE}

Whilst the Institute of Coding is still very much a "work in progress" - at the time of writing it is only just two years on from the official launch announcement, and no-one has yet graduated with an Institute degree - there are a number of notable outputs and achievements, cutting across practice, policy and research, at both the regional and national level, cutting across all five work themes. Alongside the various activities and initiatives, it also has an implicit national cohering role, especially at post-compulsory level, collaborating with other organisations working on school-level interventions to create the sustainable ecosystem to address some of the challenges articulated in this paper.

There are new degree courses (or new/majorly revised modules on existing courses) already started in 2018 and 2019, badged as "Institute of Coding": see Table I. It could be argued that some, particularly the Degree Apprenticeships, might have been started without the IoC, but it is certainly the case that the IoC has accelerated the process, not least by short-circuiting ${ }^{13}$ the often labyrinthine "quality assurance" processes in universities, as university leadership, prompted (to say the least) by the money on offer, had already signed up to the principle. There has also been a substantial amount of information interchange between IoC partners over the mechanisms of Degree Apprenticeships, as universities new to the idea started them: for the majority of IoC partners, these were the first Degree Apprenticeships the university had entered into. IoC partners were running four Degree Apprenticeships in 2018/19 and 16 (so far) in 2019/20.

In addition, there are a large number of learners on IoC "taster" courses. Of the 32,000 learners enrolled (as at the end of September 2019) on IoC courses, over 28,000 are enrolled on these. The IoC has completion rate figures for the initial cohorts on the vast majority of these, and shows a completion rate of $11 \%$, which, though low, compares favourably with the massive open online course (MOOC) norm [55]. These courses are outside the usual range of MOOCs in practice, which

\footnotetext{
${ }^{13}$ At the University of Bath, for example, the process of analysing demand was short-circuited as the IoC was, effectively, underwriting the start-up costs. Senior management then pushed for special committee meetings to get the rest of the process completed in time.
} 
Table I

IOC LEARNERS AS OF OCTOBER 2019

\begin{tabular}{lrr} 
& Courses & Learners \\
\hline BSc. etc. degree courses & 5 & 493 \\
Level 6 Degree Apprenticeships & 11 & 245 \\
Total Level 6 courses & 16 & 738 \\
Modules & 19 & 1258 \\
Total Level 6 & $\mathbf{3 5}$ & $\mathbf{1 9 9 6}$ \\
\hline MSc, etc. degree courses & 13 & 643 \\
Level 7 Degree Apprenticeships & 7 & 153 \\
Total Level 7 courses & 20 & 796 \\
Modules & 2 & 35 \\
Total Level 7 & $\mathbf{2 2}$ & $\mathbf{8 3 1}$ \\
\hline Total Degree courses & $\mathbf{1 8}$ & $\mathbf{1 1 3 6}$ \\
Total Degree Apprenticeships & $\mathbf{1 8}$ & $\mathbf{3 9 8}$ \\
\hline
\end{tabular}

[55] characterises as "primarily supporting already-educated learners". Further analysis of the IoC learner profile is on the workplan, to better understand how we can engage a wider demographic.

From a research and policy perspective, the announce of the Institute in 2015 [47] prompted the baseline research on introductory programming in UK universities [36], [37], alongside a significant renewed focus on computer science education in the UK - across research, policy and practice - further reinforced by the Royal Society's recommendations in its 2017 report on computing education [25]. As we see continued national curriculum and qualifications reform across the UK, especially in Wales from 2022, as well as further developments and enhancements of the computing curriculum in England, we should see more learners progress into university education with stronger digital skills and more computing experience; however, this landscape is also complex and fragmented, with a number of challenges [56].

\section{FUtURE WORK AND REPLICABILITY}

We have seen - and will continue to see - a number of initiatives, activities and interventions which may prove useful to other nations reforming their curricula (both compulsory school-level, as well as post-compulsory), as well as in the wider aim of developing broader - sustainable and transferable - societal digital, data, computational and engineering skills. There is a long history in the UK and internationally of university-industry partnerships and collaborations, especially focusing on $R \& D$ activities e.g. through the National Centre for Universities and Business (NCUB) ${ }^{14}$. This is especially true for engineering, but these have largely been focused on established disciplinary boundaries, for example, mechanical, automotive, aerospace (e.g. Boeing in the UK [57]). For "digital", this presents a significant widening of scope and sector coverage, from finance and professional services, through to the government and the wider public sector, as well as encompassing traditional IT, software, hardware and telecoms. This also intersects with more established work on

\footnotetext{
${ }^{14}$ The NCUB is an independent and not-for-profit membership organisation that promotes, develops and supports university-business collaboration across the UK: http://www.ncub.co.uk
}

innovation and entrepreneurship (from both fostering enterprise and entrepreneurship activities with students, as well as how universities can be more entrepreneurial and work more closely with industry e.g. Enterprise Educators $\mathrm{UK}^{15}$ ), again with strong European and international networks. Some of this work has been further reinforced by impactful work on developing digital skills by Nesta, the UK's innovation foundation [58], [59].

However, we recognise that there has been a significant corpus of activity in this space, especially internationally, linking to wider initiatives to promote and support computer science education e.g. Computer Science Education Week $\left(\right.$ CSEdWeek) ${ }^{16}$ and CSforAll ${ }^{17}$. Across the UK, the highprofile and impactful work of organisations such as Computing At School (CAS), Raspberry Pi Foundation, Code Club, Technocamps, et al., has led to a $£ 84 \mathrm{~m}$ investment in 2018 for a National Centre for Computing Education ${ }^{18}$ in England. This has also been supported by a wide range of activities (including accreditation, curriculum and qualifications development) by key professional bodies/learned societies, such as BCS, The Chartered Institute for IT and the Institution of Engineering and Technology (IET).

More specifically related to the aims and activities of the IoC, we have seen a multitude of initiatives purporting to quickly address the digital skills gap; it is thus important to evaluate what has been successful, and perhaps more importantly, not to replicate past failures. For example: highprofile "coding universities" (for example, CODE in Berlin ${ }^{19}$ ); microdegrees and MOOCs (e.g. Elements of AI, a series of free online courses created by the University of Helsinki ${ }^{20}$; industry boot camps and brokering/matching developers with the top companies (e.g. HackerRank, which is increasingly popular in UK universities ${ }^{21}$ ); public sector/civic service collaborations (e.g. Code for America ${ }^{22}$; to baselining and identification of best practice (e.g. in programming and software engineering [36]), cybersecurity education (e.g. [60], [61]) and degree accreditation [51], [62].

When establishing a model for viewing computer science education initiatives, it is apparent that there is substantial diversity between education systems - from formal school curricula through to tertiary education, as well as wider education policy and funding - and this can create obstacles when trying to understand progress made in one country and potentially replicate it in another [63], [64]. This is particularly relevant to the devolved (and diverging) educational systems of

\footnotetext{
${ }^{15}$ Enterprise Educators UK is the leading independent membership network for enterprise educators, whose purpose is to enable excellence in enterprise education: https://www.enterprise.ac.uk/

${ }^{16}$ https://csedweek.org

${ }^{17}$ https://www.csforall.org

${ }^{18}$ See: https://teachcomputing.org/

${ }^{19} \mathrm{CODE}$ is a private university of applied sciences that is embedded into the vibrant network of Berlin's digital economy: https://code.berlin/en/

${ }^{20} \mathrm{https}$ ://www.elementsofai.com

${ }^{21}$ https://www.hackerrank.com

${ }^{22}$ Code for America uses the principles and practices of the digital age to "improve how government serves the American public, and how the public improves government": https://www.codeforamerica.org
} 
the UK, as well as the variety of its disparate interventions, especially formal curricula and post-compulsory/tertiary education. There remain significant challenges, particularly around connectedness and coherency of policy, as well as bridging the gap between the expectations and evolving requirements of (higher) education and industry. However, two overarching themes are apparent:

- Firstly, such effort has to be viewed as a coordinated multi-pronged approach, requiring an overarching holistic strategy, co-designing/co-constructing/co-producing with universities, colleges, employers including but not limited to key digital industry partners, local and national government, as well as young people, parents and the wider public; it must also cohere with other related education and skills interventions, especially in national curricula and compulsory education pathways;

- Secondly, there is a need to overcome the challenges of recurrent funding and support to ensure long-term sustainability of the interventions, as well as parity of opportunity for all young learners. In essence, it must be viewed as a long-term, strategic activity, as part of core funding, aligning to related national policy priorities (especially economic policy, such as the UK Industrial Strategy [8]). Whilst we do not necessarily recommend replicating some of the policy or governance structures under which the UK operates (especially national quality assessment exercises such as the TEF), we have seen how they can provide a useful policy lever for initiatives such as the Institute.

The Institute of Coding thus aims in the longer term to fulfil an implicit national cohering role, collaborating with other organisations working on cognate interventions; in particular: providing a platform for conducting research activities; building the evidence base and informing policy; supporting degree/qualifications accreditation and standards alongside key professional bodies; as well as changing the wider perception - and economic, societal and cultural importance - of 'ICT', 'digital', 'coding' and other cognate skills. Whilst it is clear these goals will not be fully completed in a 3-5 year timescale, the IoC will provide a strong foundation for continued work in this area.

\section{ACKNOWLEDGEMENTS}

This work was supported by the Institute of Coding (IoC), which received $£ 20 \mathrm{~m}$ of funding from the Office for Students (OfS), as well as support from the Higher Education Funding Council for Wales (HEFCW).

We are grateful to the IoC Observatory staff, especially Dr Fiona MacGill (University of Bath), for the data collection. The first author is also grateful to Dr Matt Dickson (University of Bath) for discussions about undergraduate degrees and labour market returns in the UK [32], but any mistakes are the authors' alone.

\section{REFERENCES}

[1] N. Friesen, "Critical theory: Ideology critique and the myths of elearning," Ubiquity, no. 2, June 2008.
[2] M. Andreessen, "Why Software Is Eating The World," The Wall Street Journal, August 2011, available online: https://www.wsj.com/articles/ SB10001424053111903480904576512250915629460.

[3] European Commission, "Digital Single Market Scoreboard: United Kingdom,” DG CONNECT, Tech. Rep., 2018, https://ec.europa.eu/ digital-single-market/en/scoreboard/united-kingdom.

[4] E. Brynjolfsson, D. Rock, and C. Syverson, The Economics of Artificial Intelligence: An Agenda. National Bureau of Economic Research, 2018 , ch. Artificial Intelligence and the Modern Productivity Paradox: A Clash of Expectations and Statistics.

[5] Y. Dwivedi, L. Hughes, E. Ismagilova, G. Aarts, C. Coombs, T. Crick, Y. Duan, R. Dwivedi, J. Edwards, A. Eirug, V. Galanos, P. V. Ilavarasan, M. Janssen, P. Jones, A. Kumar Kar, H. Kizgin, B. Kronemann, B. Lal, B. Lucini, R. Medaglia, K. Le Meunier-FitzHugh, L. Le Meunier-FitzHugh, S. Misra, E. Mogaji, S. Sharma, J. Bahadur Singh, V. Raghavan, R. Raman, N. Rana, S. Samothrakis, J. Spencer, K. Tamilmani, A. Tubadji, P. Walton, and M. Williams, "Artificial Intelligence (AI): Multidisciplinary Perspectives on Emerging Challenges, Opportunities, and Agenda for Research, Practice and Policy," International Journal of Information Management, 2019, special Issue on "Artificial Intelligence and Business Value".

[6] OECD, "Measuring the Information Economy," Organisation for Economic Co-operation and Development, Tech. Rep., 2002.

[7] Office of National Statistics, "UK Standard Industrial Classification of Economic Activities 2007 (SIC 2007)," https://www.ons.gov.uk/methodology/classificationsandstandards/ ukstandardindustrialclassificationofeconomicactivities/uksic2007, 2009.

[8] Department for Business, Energy and Industrial Strategy, "Industrial Strategy: building a Britain fit for the future," UK Government, Tech. Rep. White Paper, 2017.

[9] T. Tryfonas and T. Crick, "Public Policy and Skills for Smart Cities: The UK Outlook," in Proc. 11th International Conference on PErvasive Technologies Related to Assistive Environments (PETRA 2018), 2018, pp. 116-117.

[10] Department for Digital, Culture, Media \& Sport, UK Government, "DCMS Sectors Economic Estimates 2018: Employment," https://www.gov.uk/government/statistics/dcms-sectors-economicestimates-2018-employment, 2018.

[11] Tech Nation, "UK Tech Nation Report 2018," https://technation.io/ insights/report-2018/, 2018.

[12] Department for Education, "Prime Minister announces $£ 20$ million Institute of Coding," https://www.gov.uk/government/news/prime-ministerannounces-20-million-institute-of-coding, 2018.

[13] CECE, "Informatics education in europe: Are we all in the same boat?" The Committee on European Computing Education, jointly established by Informatics Europe \& ACM Europe, Tech. Rep., 2017.

[14] House of Lords Select Committee on Digital Skills, "Make or Break: The UK's Digital Future,” UK Parliament, Tech. Rep. HL 111, 2015.

[15] House of Commons Science and Technology Committee, "Digital Skills Crisis," UK Parliament, Tech. Rep. HC 270, 2016.

[16] House of Lords Select Committee on Communications, "Growing Up with the Internet," UK Parliament, Tech. Rep. HL 130, 2017.

[17] T. Crick and S. Sentance, "Computing At School: Stimulating Computing Education in the UK," in Proc. 11th Koli Calling International Conference on Computing Education Research. ACM, 2011, pp. 122123.

[18] N. C. C. Brown, M. Kölling, T. Crick, S. Peyton Jones, S. Humphreys, and S. Sentance, "Bringing Computer Science Back Into Schools: Lessons from the UK," in Proc. 44th ACM Technical Symposium on Computer Science Education (SIGCSE 2013). ACM, 2013, pp. 269274.

[19] N. C. C. Brown, S. Sentance, T. Crick, and S. Humphreys, "Restart: The Resurgence of Computer Science in UK Schools," ACM Transactions on Computer Science Education, vol. 14, no. 2, pp. 1-22, 2014.

[20] Department for Education, "National curriculum in England: computing programmes of study," https://www.gov.uk/government/publications/ national-curriculum-in-england-computing-programmes-of-study, 2013.

[21] S. Arthur, T. Crick, and J. Hayward, "The ICT Steering Group's Report to the Welsh Government," Tech. Rep., September 2013, https://gov.wales/future-computer-science-and-information-technologyschools-ict-steering-group-report. 
[22] T. Crick and G. Beauchamp, "Fframwaith Cymhwysedd Digidol: Rethinking digital competencies in the new Welsh curriculum," in British Education Research Association (BERA) Conference, 2017.

[23] F. Moller and T. Crick, "A University-Based Model for Supporting Computer Science Curriculum Reform," Journal of Computers in Education, vol. 5, no. 4, pp. 415-434, 2018 .

[24] Royal Society, "Shut down or restart?: The way forward for computing in UK schools," Royal Society, Tech. Rep., 2012, https:// royalsociety.org/topics-policy/projects/computing-in-schools/report/.

[25] _ , "After the reboot: computing education in UK schools," Royal Society, Tech. Rep., 2017, https://royalsociety.org/topics-policy/projects/ computing-education/.

[26] J. H. Davenport, T. Crick, A. Hayes, and R. Hourizi, "The Institute of Coding: Addressing the UK Digital Skills Crisis," in Proc. Computing Education Practice 2019. ACM, 2019, pp. 10:1-10:4.

[27] UK Commission for Employment and Skills, "Sector insights: skills and performance challenges in the digital and creative sector," https://www.gov.uk/government/publications/sector-insights-skillsand-performance-challenges-in-the-digital-and-creative-sector, 2015.

[28] Department for Business, Innovation and Skills, "The Returns to Higher Education Qualifications," https://www.gov.uk/government/uploads/ system/uploads/attachment_data/file/32419/11-973-returns-to-highereducation-qualifications.pdf, 2011.

[29] Sir Nigel Shadbolt, "Shadbolt Review of Computer Sciences Degree Accreditation and Graduate Employability," https://www.gov.uk/ government/uploads/system/uploads/attachment_data/file/518575/ind16-5-shadbolt-review-computer-science-graduate-employability.pdf, 2016.

[30] Sir Bill Wakeham, "Wakeham Review of STEM Degree Provision and Graduate Employability," https://www.gov.uk/government/uploads/ system/uploads/attachment_data/file/518582/ind-16-6-wakehamreview-stem-graduate-employability.pdf, 2016.

[31] Department for Education, "Longitudinal Education Outcomes (LEO) Data Set," https://www.gov.uk/government/statistics/graduateoutcomes-longitudinal-education-outcomes-leo-data, 2017.

[32] —- "Undergraduate degrees: relative labour market returns," https://www.gov.uk/government/publications/undergraduate-degreesrelative-labour-market-returns, 2018.

[33] BBC, "Which university courses boost graduates' wages the most?" https://www.bbc.co.uk/news/education-44413086, 2018.

[34] Higher Education Statistics Agency, "Higher Education Leavers Statistics: UK, 2016/17 - Salary and location of leavers in employment," https://www.hesa.ac.uk/news/28-06-2018/sfr250-highereducation-leaver-statistics-employment, 2018.

[35] J. H. Davenport, A. Hayes, R. Hourizi, and T. Crick, "Innovative Pedagogical Practices in the Craft of Computing," in Proc. 4th International Conference on Learning and Teaching in Computing and Engineering (LaTiCE 2016). IEEE, 2016, pp. 115-119.

[36] E. Murphy, T. Crick, and J. H. Davenport, "An Analysis of Introductory Programming Courses at UK Universities," The Art, Science, and Engineering of Programming, vol. 1(2), no. 18, pp. 18-1-18-23, 2017.

[37] Simon, R. Mason, T. Crick, J. H. Davenport, and E. Murphy, "Language Choice in Introductory Programming Courses at Australasian and UK Universities," in Proc. 49th ACM Technical Symposium on Computer Science Education (SIGCSE 2018). ACM, 2018, pp. 852-857.

[38] Department for Business, Innovation and Skills, "The Browne report: higher education funding and student finance," https://www.gov.uk/government/publications/the-browne-report-highereducation-funding-and-student-finance, 2010.

[39] OECD, Education at a Glance 2016: OECD Indicators. Paris: OECD Publishing, 2016.

[40] C. Callender and G. Mason, "Does Student Loan Debt Deter Higher Education Participation? New Evidence from England," The Annals of the American Academy of Political and Social Science, vol. 671, pp. 20-48, 2017.

[41] C. Campbell, M. Jimenez, and C. Arrozal, "Prestige or education: college teaching and rigor of courses in prestigious and non-prestigious institutions in the U.S." To appear in Higher Education, 2018.

[42] J. Gillard, "An initial analysis and reflection of the metrics used in the Teaching Excellence Framework in the UK," Perspectives: Policy and Practice in Higher Education, vol. 22, no. 2, pp. 49-57, 2017.
[43] Department for Business, Innovation and Skills, "Government rollsout flagship Degree Apprenticeships," https://www.gov.uk/government/ news/government-rolls-out-flagship-degree-apprenticeships, 2015.

[44] HM Revenue \& Customs, "Apprenticeship Levy," https://www.gov.uk/ government/publications/apprenticeship-levy/apprenticeship-levy, 2016.

[45] Institute for Apprenticeships, "Digital and technology solution specialist (degree)," https://www.instituteforapprenticeships.org/apprenticeshipstandards/digital-and-technology-solution-specialist-degree/, August 2018.

[46] S. Watt, "Value of co-op year," Private communication to XXX (removed for double-blind reviewing), 2017.

[47] HM Government, "Chancellor's speech to GCHQ on cyber security: Chancellor lays out new plan for $£ 1.9$ billion cyber investment, and details seven more departments that have settled ahead of the Spending Review," https://www.gov.uk/government/speeches/chancellors-speechto-gchq-on-cyber-security, 2015

[48] BCS, The Chartered Institute for IT, "Guidelines on course accreditation," https://www.bcs.org/category/7066, 2018.

[49] D. Cotton, W. Miller, and P. Kneale, "The Cinderella of academia: Is higher education pedagogic research undervalued in UK research assessment?" Studies in Higher Education, vol. 43, pp. 1625-1636, 2018.

[50] Simon, "The Koli Calling Community," in Koli Calling $2016 . \quad$ New York: ACM, 2016, pp. 101-109.

[51] T. Crick, J. H. Davenport, P. Hanna, A. Irons, and T. Prickett, "Computer Science Degree Accreditation in the UK: A Post-Shadbolt Review Update," in Proceedings of Computing Education Practice, 2020, pp. $1-4$.

[52] S. Sentance and J. Waite, "Computing in the classroom: Tales from the chalkface," it-Information Technology, vol. 60, no. 2, pp. 103-112, 2018.

[53] S. Sentance and A. Csizmadia, "Computing in the curriculum: Challenges and strategies from a teacher's perspective," Education and Information Technologies, vol. 22, no. 2, pp. 469-495, 2017.

[54] S. Sentance, M. Dorling, A. McNicol, and T. Crick, "Grand Challenges for the UK: Upskilling Teachers to Teach Computer Science Within the Secondary Curriculum," in Proc. WiPSCE 2012. ACM, 2012, pp. $82-85$.

[55] J. Reich and J. A. Ruipérez-Valiente, "The MOOC Pivot," Science, vol. 363, no. 6423, pp. 130-131, 2019.

[56] P. E. Kemp and M. G. Berry, "The Roehampton Annual Computing Education Report," University of Roehampton, Tech. Rep., May 2019, https://www.bcs.org/more/bcs-academy-of-computing/theroehampton-annual-computing-education-report/.

[57] Boeing UK, "Universities, Research and Technology," https://www.boeing.co.uk/boeing-in-the-uk/research-and-technology/ universities-research-and-technology.page, 2020

[58] J. Orlik, "Delivering digital skills: A guide to preparing the workforce for an inclusive digital economy," Readie and Nesta, Tech. Rep., April 2018, https://www.nesta.org.uk/report/delivering-digital-skills/.

[59] J. Djumalieva and C. Sleeman, "Which digital skills do you really need? Exploring employer demand for digital skills and occupation growth prospects," Nesta, Tech. Rep., July 2018, https://www.nesta.org.uk/ report/which-digital-skills-do-you-really-need/.

[60] T. Crick, J. H. Davenport, A. Irons, and T. Prickett, "A UK Case Study on Cybersecurity Education and Accreditation," in Proceedings of 49th Annual Frontiers in Education Conference (FIE 2019), 2019.

[61] T. Crick, J. H. Davenport, A. Irons, S. Pearce, and T. Prickett, "Maintaining the Focus on Cybersecurity in UK Higher Education," ITNOW, vol. 61, no. 4, pp. 46-47, 2019.

[62] T. Crick, J. H. Davenport, P. Hanna, A. Irons, S. Pearce, and T. Prickett, "Repositioning BCS Degree Accreditation," ITNOW, vol. 62, no. 1, pp. $50-51,2020$.

[63] P. Hubwieser, "The Darmstadt model: A first step towards a research framework for computer science education in schools," in Proc. ISSEP 2013, 2013, pp. 1-14.

[64] K. Falkner, S. Sentance, R. Vivian, S. Barksdale, L. Busuttil, E. Cole, C. Liebe, F. Maiorana, M. M. McGill, and K. Quille, "An International Comparison of K-12 Computer Science Education Intended and Enacted Curricula," in Proc. 19th Koli Calling International Conference on Computing Education Research. ACM, 2019, pp. 11-10. 